\title{
Code Simulations and Death: Processing of Emotional Distress
}

Jane D. Leavy

Calvin J. Vanderhoff

Patricia K. Ravert

Brigham Young University - Provo, patricia-ravert@byu.edu

Follow this and additional works at: https://scholarsarchive.byu.edu/facpub

Part of the Critical Care Nursing Commons, and the Other Nursing Commons

\section{Original Publication Citation}

Leavy, J., Vanderhoff, C. J., \& Ravert, P. (2011). Code simulations and death: Processing of emotional distress. International Journal of Nursing Education Scholarship. 8(iss), art 16.

\section{BYU ScholarsArchive Citation}

Leavy, Jane D.; Vanderhoff, Calvin J.; and Ravert, Patricia K., "Code Simulations and Death: Processing of Emotional Distress" (2011). Faculty Publications. 5276.

https://scholarsarchive.byu.edu/facpub/5276

This Peer-Reviewed Article is brought to you for free and open access by BYU ScholarsArchive. It has been accepted for inclusion in Faculty Publications by an authorized administrator of BYU ScholarsArchive. For more information, please contact ellen_amatangelo@byu.edu. 


\title{
International Journal of Nursing Education Scholarship
}

Volume 8, Issue 1

2011

Article 16

\section{Code Simulations and Death: Processing of Emotional Distress}

\author{
Jane D. Leavy* Calvin J. Vanderhoff ${ }^{\dagger}$ \\ Patricia K. Ravert
}

*Utah Valley Regional Medical Center, leavy.jane@gmail.com

${ }^{\dagger}$ Sharp Grossmont Hospital, calvinsdsu @ yahoo.com

‡Brigham Young University, patricia_ravert@byu.edu 


\title{
Code Simulations and Death: Processing of Emotional Distress
}

\author{
Jane D. Leavy, Calvin J. Vanderhoff, and Patricia K. Ravert
}

\begin{abstract}
It is important for nursing students to be exposed to critical patient care scenarios because high stress clinical situations, such as patient codes, occur unexpectedly and infrequently in the clinical setting. In addition, it is important for nursing students to be exposed to the reality of patient death in order to help them overcome fears associated with death and to develop effective coping strategies. Students may or may not have an opportunity to deal with patient codes or patient death in the clinical setting, therefore simulation labs provide students with the opportunity to practice important clinical skills and discuss emotions in a safe environment. Although there is some research on the benefits of incorporating end-of-life patient care scenarios in simulation labs, there is no research that analyzes students' perceptions of the benefits of participating in simulated code scenarios and their emotions following patient simulated death. A pilot study was conducted to assess students' views on the benefits of participating in simulated code scenarios in which a patient dies and the effectiveness of the debriefing session in processing emotions related to the lab experience.
\end{abstract}

KEYWORDS: Code simulations, debriefing, emotions, death and dying, student perceptions 
With the increase in patient acuity and decrease in available teaching clinical space for nursing students in the United States, nurse educators are turning to human patient simulation as a valuable teaching tool (Simko, McGinnis, Henry, \& Kolesar, 2009). High stress clinical situations, such as cardiac arrests, occur unexpectedly and infrequently in hospitals, and nurses report that they often feel unprepared to handle these critical situations (Linnard, 1996). It is valuable to expose nursing students to critical patient care scenarios in a simulation lab first rather than in a hospital setting where real patients' lives are at risk (Simko, et al.). In addition, simulation labs provide nursing students with the opportunity to practice critical response skills and to increase skill performance accuracy and speed (Linnard).

Following simulation experiences, many educators hold a debriefing session to allow students to reflect on their performance (Simko et al., 2009). Nurse educators often address issues such as skill execution, teamwork, and communication in simulation lab debriefing (Simko et al.). Nursing students only have a brief exposure to critical patient care scenarios in the simulation lab, and thus the debriefing session is important in providing students further exposure to the knowledge and skills used during the simulation experience. As students reflect on their simulation experience, they are more likely to retain the knowledge and skills they obtained (Ackermann, 2009).

Although teaching and discussion are important aspects of debriefing following critical patient care scenarios such as code scenarios, addressing students' emotions is an often over-looked element. Many undergraduate programs fail to adequately prepare nursing students to personally and professionally care for dying patients (Leighton \& Dubas, 2009). According to Lange, Thom, and Kline (2008), it is important that nursing students are exposed to end-of-life educational opportunities to help them identify and process anxieties about death. Dealing with death is an emotionally difficult experience for healthcare workers in the clinical setting (Hobgood, Harward, Newton, \& Davis, 2005). All nurses across various practice settings will be faced with death and dying at some point. Often, death is viewed as a failure rather than a natural process of life (Dunn, Otten, \& Stephens, 2005). In many code situations in the clinical setting, patients die even when healthcare providers perform all the correct skills (Peberdy et al., 2008). Nursing students may or may not experience death or dying in a supervised clinical setting, therefore exposing them to a simulated death is valuable to help them confront feelings and fears concerning death (Dunn et al.).

Addressing students' emotions following patient simulated death not only helps develop appropriate coping mechanisms, but also may help increase 
cognitive functioning in real-life patient code situations (Ben-Zur, 2009). High levels of anxiety in stressful situations may lead to mental blocks and poor skill execution (Pintrich \& Schunk, 2002). By exposing nursing students to death in simulated patient code scenarios and addressing students' emotions in debriefing sessions, nursing educators can help students improve quality of patient care in clinical code situations and help them learn how to appropriately communicate feelings regarding death and dying following patient demise (Ferrell et al., 2005; Frommelt, 2003; Lange et al., 2008).

There is little research available on students' views of the benefits of participating in simulation labs in which patients die. Several researchers have studied the benefit of simulation as an effective method to help students deal with issues in end-of-life patient care (Hamilton, 2010; Leighton \& Dubas, 2009). Upon reviewing the current literature, we could not locate any studies directly addressing students' perceived benefits of participating in simulated code scenarios and students' emotions following patient simulated death. In this article we briefly summarize the literature regarding simulation use to educate students about patient death. We also report findings from a study assessing nursing students' perceptions of the benefit of code scenarios in gaining clinical competence and processing emotions following patient death in human patient simulation labs. The students' perceptions of the effectiveness of the debriefing session following the simulation lab in processing emotions are also reported.

\section{REVIEW OF THE LITERATURE}

According to Leighton and Dubas (2009), nursing students may experience a range of emotions and low levels of self-efficacy when caring for patients near death and for their families. Although nursing students may experience emotional distress in providing end-of-life care, they also experience benefits such as understanding the value of holistic care, the need of preserving patient dignity, and the importance of family members' roles. Providing students with opportunities to gain identified competencies in the clinical environment is often difficult. In clinical situations involving patient death, clinical staff may have concerns that students will say the wrong thing to the patient or family, or not know how to appropriately respond in situations in which patients are dying (Gordon, Wilkerson, Shaffer, \& Armstrong, 2001). In the simulation laboratory, students can experience an interactive, hands-on experience in a safe, risk-free environment, through the use of a patient simulator (Leighton \& Dubas). This technology includes high fidelity mannequins equipped with heart, lung, and bowel sounds, as well as voice projection capabilities to resemble human functions. One newly researched use for simulation in nursing education is to 
introduce students to situations presenting types of end-of-life issues encountered in actual nursing practice (Hamilton, 2010).

To meet the goals of changing students' perceptions of death and dying, decreasing fears and anxieties of confronting end-of-life situations, and assisting with developing appropriate coping mechanisms, both students and faculty ought to be receptive to feedback during the reflection process of debriefing after the simulation experience (Hamilton, 2010). As effective debriefing helps students to integrate and internalize issues related to end-of-life care, they will find intrinsic motivation to provide optimal care with effective coping strategies (Ryan \& Deci, 2000). The overall goal of end-of-life care simulated clinical experiences and effective debriefing is to help students transfer knowledge and experience from the simulation lab to the practicing nursing community and to positively influence quality of care given to patients facing end-of-life situations (Hamilton).

\section{STUDY METHODOLOGY}

\section{Brigham Young University Simulation Experiences}

Brigham Young University utilizes high-fidelity simulation experiences in three of the six semesters in the nursing program. The simulation experiences are conducted outside of the students' clinical experience during a scheduled lab. A faculty member facilitates the labs and runs the debriefing sessions following the labs. The College of Nursing employs undergraduate nursing students to set-up and take-down the lab equipment, operate the computer, and serve as the simulated patient voice, thus freeing the faculty member to facilitate the labs. High-fidelity simulation experiences are introduced in the third semester of a sixsemester nursing curriculum during the medical/surgical coursework. Students complete five simulated clinical experiences during this semester, which include chest pain management, ruptured diverticulum, chronic heart failure exacerbation, gastrointestinal bleed secondary to aspirin abuse, and diabetic ketoacidosis. In this study, the faculty member selected the diabetic ketoacidosis scenario as the third semester scenario in which the patient would code and eventually die.

Fourth semester students participate in several high-fidelity simulation experiences, which include post-partum hemorrhage, pregnancy-induced hypertension, shoulder dystocia, prolapsed cord, pediatric acute asthma attack, and pediatric diabetic ketoacidosis. During this semester, students study pediatric nursing and labor and delivery. In this study and for the fourth semester students, the pediatric acute asthma attack scenario simulated a patient code and death. 
Fifth semester students study critical care nursing and are required to participate in one lab with four code scenarios. Three patients are successfully resuscitated following correct intervention implementation, and one selected patient dies even following correct resuscitation efforts. The four code scenarios include cardiac arrest, respiratory arrest, gastrointestinal bleed, and drug overdose. In this study, the gastrointestinal bleed scenario served as the fifth semester scenario in which the patient died following resuscitation efforts.

\section{Instrument}

After a search of the literature, no reliable survey instrument was located. Therefore, a six-item survey was designed to assess students' perceptions of the benefit of code simulation experiences in which the patient died. Refer to Table 1.

\section{Table 1}

\section{Code Simulation Instrument}

Code Simulation Lab Survey

Have you ever had a patient die at work or in clinical? (Please circle)

Yes No

Did you feel you had knowledge and skill to deal with the emergent simulation?

(Please circle)

$\begin{array}{lllllllllllll}\text { Not competent } & 0 & 1 & 2 & 3 & 4 & 5 & 6 & 7 & 8 & 9 & 10 & \text { Fully Competent }\end{array}$

What were your emotions as the patient was coding?

What were your emotions when the patient died?

How effective do you think the debriefing was in processing your thoughts and emotions? What could be improved on in the debriefing?

How beneficial did you think the simulation was?

$\begin{array}{lllllllllllll}\text { Not beneficial } & 0 & 1 & 2 & 3 & 4 & 5 & 6 & 7 & 8 & 9 & 10 & \text { Beneficial }\end{array}$

If you think this was at least half beneficial (five or higher), why? 
The concepts and items were derived from current end-of-life and simulation literature and reviewed by experts to establish face and content validity. The survey consisted of four open-ended questions that assessed the students' emotions and their thoughts on the effectiveness of the debriefing session following the simulation. In addition, the survey measured students' perceptions of their competency and their views on the benefits of the simulation lab experience using a Likert scale (0-10 with zero representing not competent or not beneficial and ten representing totally competent or totally beneficial).

Following the simulation labs, the researchers asked for volunteers to participate in a focus group to collect additional qualitative data on the students' perceptions of the benefits of the code simulation lab experience. Refer to Table 2 for questions used in the focus group.

\section{Table 2}

\section{Code Simulation Focus Group}

\section{Focus Group Questions}

1. What were your thoughts and emotions when the patient coded?

2. What were your thoughts and emotions when the patient died?

3. How helpful was the debriefing in processing your emotions and addressing your concerns?

\section{Description of Participants}

Participants were nursing students in the third, fourth, or fifth semester of the nursing program. The age range of the students was 19 to 26 . The average student GPA was 3.86 with a range of 3.73 to 4.0. Of the 176 students who participated in the scheduled simulation experiences, approximately $85 \%$ completed the survey $(n=149)$. Of those who completed the survey, approximately $91 \%$ were female $(n=136)$ and $9 \%$ were male $(n=13)$. Seven of 
the students who completed the survey volunteered to participate in the focus group session scheduled for a later time.

\section{Procedures}

After obtaining Institutional Review Board approval, a faculty member not involved in the research made an announcement regarding the study and the survey at the beginning of the scheduled code simulation labs. The students were ensured that their responses would remain confidential and their participation in the study was completely voluntary.

Following the simulation experience, students who were willing to participate in the study signed consent forms and completed the surveys. Of those consenting, seven volunteers were recruited to participate in a focus group held on a separate day. Participant identifiers and survey results remained separated. The survey data was entered into the Statistical Package for Social Sciences (SPSS) version 18 for statistical analysis. Data from the Likert scale were entered into SPSS and analyzed using descriptive statistics (means, standard deviations). Marked differences between the means from the surveys of participants with previous experience with patient death and participants with no previous experience with patient death were tested for statistical significance to determine if the results were likely or not likely due to chance. Qualitative data was transcribed from the written answers as well as from the focus group.

\section{RESULTS}

Refer to Table 3 for the means and standard deviations of the competency and beneficial scale scores from the participants' surveys. Refer to Table 4 for the results of simple $t$-tests analyzing the differences between the overall means of the group with no prior experience with patient death in the clinical and work setting and the group with prior experience with patient death in the clinical and work setting. 
Table 3

Means and Standard Deviations of Competency and Beneficial Scale Scores

\begin{tabular}{|c|c|c|c|c|}
\hline Death Experience & Scale & Semester & $M$ & $S D$ \\
\hline $\begin{array}{l}\text { No } \\
(n=125)\end{array}$ & Competency & $\begin{array}{l}3 \\
4 \\
5 \\
\text { Overall }\end{array}$ & $\begin{array}{l}4.47 \\
4.50 \\
4.55 \\
4.51\end{array}$ & $\begin{array}{l}0.71 \\
1.83 \\
1.71 \\
0.04\end{array}$ \\
\hline & Beneficial & $\begin{array}{l}3 \\
4 \\
5 \\
\text { Overall }\end{array}$ & $\begin{array}{l}8.69 \\
8.22 \\
8.79 \\
8.56\end{array}$ & $\begin{array}{l}1.47 \\
1.36 \\
1.21 \\
0.26\end{array}$ \\
\hline $\begin{array}{l}\text { Yes } \\
(n=14)\end{array}$ & Beneficial & $\begin{array}{l}3 \\
4 \\
5 \\
\text { Overall } \\
\\
3 \\
4 \\
5 \\
\text { Overall }\end{array}$ & $\begin{array}{l}4.00 \\
3.67 \\
5.12 \\
4.26 \\
\\
8.50 \\
8.33 \\
8.82 \\
8.55\end{array}$ & $\begin{array}{l}2.00 \\
2.08 \\
2.12 \\
0.75 \\
\\
1.20 \\
1.53 \\
1.33 \\
0.25\end{array}$ \\
\hline
\end{tabular}

Note. Semester $3=$ medical/surgical, $4=$ pediatrics, $5=$ ICU.

\section{Competence Scale Scores}

The overall mean for competence for the group of participants who had no prior experience with patient death was higher than the group who had prior experience with patient death. The difference, however, was not statistically significant. This was probably influenced by the fact that the sample size in the second group was much smaller.

\section{Beneficial Scale Scores}

The overall means of the beneficial scale scores for both groups of participants with and without prior experience with patient death were nearly equivalent. The overall mean of the group with no prior experience with patient 
death was slightly higher than the group with prior experience, but the difference was not statistically significant.

\section{Table 4}

Comparison of Overall Mean Scores

\begin{tabular}{lccccc}
\hline Scale & $\bar{x}_{1}$ & $\bar{x}_{2}$ & $S E M$ & $t$ & $p$ \\
\hline Competency & 4.51 & 4.26 & 0.203 & 1.232 & $>0.05$ \\
Beneficial & 8.56 & 8.55 & 0.072 & 0.139 & $>0.05$
\end{tabular}

Note. $\bar{x}_{1}=$ overall mean of scores from participants with no prior experience with patient death in the clinical or work setting $(n=135) . \bar{x}_{2}=$ overall mean of scores from participants with prior experience with patient death in the clinical or work setting $(n=14)$.

\section{Qualitative Results}

The comments from the open-ended questions in the survey and the responses recorded from the focus group were analyzed using standard qualitative methods, which included open and selective coding procedures. Inductive analysis was then used to locate themes (Patton, 1990). Initially, two researchers used open coding to identify themes. These themes were cross-checked and refined through discussion among the investigators. Differences in researcher interpretation were discussed until consensus was reached following the independent coding, which ensured trustworthiness (Denzin \& Lincoln, 2000; Lincoln \& Guba, 1985). After consensus was reached, modifications were made to the themes. The findings were reviewed by a researcher who had not participated in the study to ensure descriptions and themes were clear and representative of the responses.

Following the qualitative analysis of the survey comments and focus group responses, three themes were identified. The first theme was that students felt there was insufficient processing of emotions in the debriefing session following the simulation lab. The second theme was that the simulations did not feel like real-life to students. The third theme was that the students thought the simulation labs were beneficial in their purpose. Several participant exemplary responses related to the identified themes are presented below. 
Emotional processing. One participant stated, "I really wish there was a longer debriefing.... I was angry and I couldn't talk about it. I wanted to deal with the here and now and not bottle them [emotions] up." Similarly, another added, "It adds more stress if you don't talk about it. I felt lonely when I didn't talk about it and I think emotionally the best thing to do is talk about it."

Unrealistic simulations. Participant comments describing the second theme included, "In simulation you knew that a simulator can't really die and I'm sure I would be more attached to a real patient."; and "The simulation didn't feel like a real-life situation because the patient was not a real person." Another student concurred, "In the simulation lab, you knew that the mannequin could come back to life, and that doesn't happen in real-life."

Beneficial experience. Several comments illustrated this theme: "I would deal better with critical care because I would have had more exposure with codes/death."; "I really enjoyed [simulation] lab when despite all our efforts, the patient died. It was really life affirming and I feel more prepared now for having a patient die."; and "When the patient died I did so much better the next week. I was much more aware and felt prepared for anything." Other students' statements focused on the contextual aspect, "It's a scary situation in a safe setting which promotes a lot of learning."; "I was grateful to experience this situation in lab rather than in a hospital setting first."; and "It is good practice to learn how to prioritize especially in an emergent situation and how to work together as a team."

\section{DISCUSSION}

Researchers have established that nursing students feel emotional distress when providing end-of-life care (Leighton \& Dubas, 2009). This study supported there is benefit in exposing nursing students to educational opportunities addressing patient death in order to help students process anxieties and develop effective coping skills (Lange et al., 2008). Because nursing students may or may not experience death or dying in the clinical setting, it is important to provide opportunities for nursing students to confront their fears and concerns about death is in an alternate setting (Dunn et al., 2005). Through constructive discussion of students' emotions and concerns in the debriefing sessions following simulation labs, faculty can help the students to transfer positive coping and communication skills from the simulation lab to the practicing nursing community (Hamilton, 2010). 
This study revealed that both groups of participants felt somewhat incompetent to respond to the code situation in the simulation lab. An unexpected finding, however, was that the overall mean of the competence scale scores for the group of participants with no previous experience with patient death was higher compared to the overall mean of the group with previous experience with patient death. This was unexpected because the researchers hypothesized that students with previous experience with death would feel more competent to deal with a code situation. The researchers further hypothesized that this phenomenon may be because students without experience with death in the clinical or work setting may not fully comprehend the competency necessary to deal with code situations. However, a simple $t$-test revealed no statistically significant difference. Although there was no significant difference shown in this study, a future study with more equivalent group sizes may prove to be statistically significant.

This study also revealed that both groups of participants felt the code simulations in which a patient died were beneficial to their learning. The overall means of the beneficial scale scores for both groups were nearly equivalent. The participants with prior experience with patient death felt that the simulation experience was slightly less beneficial than the participants with no prior experience with death; but the difference was not statistically significant.

Another finding was that the participants felt the simulations did not feel real, but were helpful in preparing them for real-life code scenarios. In addition, participants identified that there was inadequate time devoted to processing emotions in the debriefing session following the simulation labs. Some participants expressed a desire for more in-depth discussion of emotions to help address their concerns.

\section{Implications and Limitations}

The results indicate students from each of the semesters felt scenarios incorporating patient death and emotional debriefing are important to their learning in the clinical setting. Therefore, it may be valuable for the faculty to continue to incorporate code scenarios that include patient death in the simulation labs. This study was conducted in one college and additional studies at various locations with more diverse populations need to be conducted to determine if code scenarios involving patient death and emotional debriefing are valuable to all nursing students. In addition, researchers may want to investigate differences between death scenarios with adult and pediatric simulators. In this study, adult and pediatric simulations were analyzed in a similar manner. 
Students participating in this study indicated more in-depth emotional debriefing should follow patient simulated death. For future simulations, faculty may want to consider spending more time addressing students' emotional concerns and attitudes about patient death following simulation labs. A limitation to this study is that different faculty facilitated the lab experience in each semester, and the faculty may have conducted the debriefing sessions differently. The researchers did not develop a standardized outline of questions addressing student thoughts and emotions for the debriefing session. In future studies, researchers should consider formulating a simulation dialogue and debriefing outline to standardize the experience even when facilitated by different faculty members.

Another limitation to this study is that the students may have had previous personal experience with death outside of the work or clinical setting. This confounding variable may have affected the results of the students who reported that they had no previous experience with death in the clinical or work setting. In future research, researchers should take this variable into consideration when assessing students' previous experience with death.

\section{RECOMMENDATIONS AND CONCLUSION}

The results from this study may serve to inform researchers to conduct multi-site projects to further address students' perceptions on the benefits of participating in simulated code scenarios and their emotions following patient simulated death. Researchers could investigate the differences in male and female participant responses to simulated patient code experiences. Future research could also include video capture of participant responses to patient code and death to further develop educational experiences for nursing students. Additional information can be utilized to better educate nursing students on how to skillfully respond and effectively cope with code and death in the clinical setting.

\section{REFERENCES}

Ackermann, A. D. (2009). Investigation of learning outcomes for the acquisition and retention of CPR knowledge and skills learned with the use of highfidelity simulation. Clinical Simulation in Nursing, 5, e213-e222. doi: 10.1016/j.ecns.2009.05.002.

Ben-Zur, H. (2009). Coping styles and affect. International Journal of Stress Management, 16, 87-101. doi:10.1037/a0015731 
Denzin, N. K., \& Lincoln, Y. S. (Eds.). (2000). Handbook of qualitative research (2nd ed.). Thousand Oaks, CA: Sage.

Dunn, K. S., Otten, C., \& Stephens, E. (2005). Nursing experience and the care of dying patients. Oncology Nursing Forum, 32, 97-104. doi:10.1188/05.ONF.97-104.

Ferrell, B. R., Virani, R., Grant, M., Rhome, A., Malloy, P., Bednash, G., et al. (2005). Evaluation of the end-of-life nursing education consortium undergraduate faculty training program. Journal of Palliative Medicine, 8, 107-114. doi:10.1089/jpm.2005.8.107

Frommelt, K. H. (2003). Attitudes toward care of the terminally ill: An educational intervention. American Journal of Hospice and Palliative Medicine, 20, 13-22. Doi:10.1177/104990910302000108

Gordon, J. A., Wilkerson, W. M., Shaffer, D. W., \& Armstrong, E. G. (2001). 'Practicing' medicine without risk: Students' and educators' responses to high-fidelity patient simulation. Academic Medicine, 76, 469-472.

Hamilton, C. (2010). The simulation imperative of end-of-life education. Clinical Simulation in Nursing, 6, e131-e138. doi:10.1016/j.ecns.2009.08.002

Hobgood, C., Harward, D., Newton, K., \& Davis, W. (2005). The educational intervention "GRIEVING" improves the death notification skills of residents. Academic Emergency Medicine, 12, 296-301 doi:10.1197/j.aem.2004.12.008.

Lange, M., Thom, B., \& Kline, N. E. (2008). Assessing nurses' attitudes toward death and caring for dying patients in a comprehensive cancer center. Oncology Nursing Forum, 35, 955-959. doi:10.1188/08.ONF.955-959

Leighton, K., \& Dubas, J. (2009). Simulated death: An innovative approach to teaching end-of-life care. Clinical Simulation in Nursing, 5, 223-230. doi: 10.1016/j.ecns.2009.04.093.

Lincoln, Y. S., \& Guba, E. G. (1985). Naturalistic inquiry. Newbury Park, CA: Sage.

Linnard, L. R. (1996). The effect of a skills algorithm on nursing students' response rate, skill accuracy, and reported attention management during simulated cardiopulmonary arrests (Doctoral dissertation). University of San Francisco, California. (AAT 9721827).

Patton, M. Q. (1990). Qualitative evaluation and research methods (2nd ed.). Newbury Park, CA: Sage.

Peberdy, M. A., Ornato, J. P., Larkin, L., Braithwaite, S., Kashner, T. M., Carrey, S. M., et al. (2008). Survival from in-hospital cardiac arrest during nights and weekends. Journal of the American Medical Association, 299, 785792. doi:10.1001/jama.299.7.785. 
Pintrich, P. R., \& Schunk, D. H. (2002). Motivation in education: Theory, research, and application (2nd ed.). Upper Saddle River, NJ: Prentice Hall.

Ryan, R. M, \& Deci, E. L. (2000). Intrinsic and extrinsic motivations: Classic definitions and new directions. Contemporary Educational Psychology, 25, 54-67. doi:10.1006/ceps.1999.1020.

Simko, L. C., McGinnis, C. A., Henry, R., \& Kolesar, A. L. (2009). Use of simulation in mock code preparation. Clinical Simulation in Nursing, 5, S13-S14. 